\title{
La activación plaquetaria como factor desencadenante de la inflamación y la ateroesclerosis
}

\author{
Platelet activation as a trigger factor for inflammation and atherosclerosis
}

\author{
Santiago J. Custodio-Chablé, Ruth A. Lezama y Elba Reyes-Maldonado*
}

Escuela Nacional de Ciencias Biológicas, Instituto Politécnico Nacional, Ciudad de México, México

\begin{abstract}
Resumen
Las plaquetas, además de participar en la ateroesclerosis, desempeñan un papel muy activo en la respuesta inmunitaria de esta enfermedad, ya que tienen la capacidad de interaccionar con diversas células inflamatorias, además de secretar citocinas, quimiocinas, factores de crecimiento, etc. Las funciones de las plaquetas van más allá de su interacción con el endotelio, pues participan en crear un ambiente inflamatorio, lo que contribuye a la pérdida de la homeostasis. Por otra parte, las micropartículas derivadas de plaquetas inducen la activación de otras plaquetas y de células endoteliales, y el reclutamiento de leucocitos. Por todo lo anterior, las plaquetas y el ambiente inflamatorio pueden considerarse como posibles blancos terapéuticos para evitar el desarrollo de la ateroesclerosis y los eventos asociados a esta.
\end{abstract}

Palabras Clave: Aterosclerosis. Inflamación. Plaquetas.

\begin{abstract}
Platelets, in addition to participating in atherosclerosis, play a very active role in the immune response of this disease since they have the ability to interact with various inflammatory cells, in addition to secreting cytokines, chemokines, growth factors, etc. The functions of platelets go beyond their interaction with the endothelium, as they participate in creating an inflammatory environment, which contributes to the loss of homeostasis. On the other hand, platelet-derived microparticles induce the activation of other platelets, of endothelial cells and in recruiting leukocytes. For all the above, platelets and the inflammatory environment can be considered as possible therapeutic targets to prevent the development of atherosclerosis and the events associated with it.
\end{abstract}

Key Words: Atherosclerosis. Inflammation. Platelets.

\section{Introducción}

La ateroesclerosis se cataloga como una enfermedad vascular inflamatoria crónica, progresiva, con elevada participación inmunitaria'. Esta enfermedad se caracteriza por la acumulación de lípidos, especialmente la fracción conocida como lipoproteína de baja densidad (LDL), por debajo de la capa íntima de los vasos sanguíneos, convirtiéndose así en un potente estimulador de la respuesta inmunitaria en las células

\section{Correspondencia:}

*Elba Reyes-Maldonado

Prolongación de Carpio y Plan de Ayala

Col. Santo Tomas, Del. Miguel Hidalgo

C.P. 11340, Ciudad de México, México

Fecha de recepción: 11-09-2018

Fecha de aceptación: 08-02-2019

E-mail: elbareyesm@gmail.com
Cir Cir. 2020;88(2):233-243

Contents available at PubMed www.cirugiaycirujanos.com

0009-7411/C 2019 Academia Mexicana de Cirugía. Publicado por Permanyer. Este es un artículo open access bajo la licencia CC BY-NC-ND (http://creativecommons.org/licenses/by-nc-nd/4.0/). 
endoteliales vasculares ${ }^{2}$. Si bien el factor de riesgo más conocido y estudiado para el desarrollo de ateroesclerosis es la obesidad, este no es el único, ya que se ha descrito que la microbiota intestinal puede generar lípidos que desarrollen placas ateroescleróticas $^{3}$. El papel que desempeñan las plaquetas en la ateroesclerosis, sobre todo en su desarrollo, aún no es comprendido del todo. La rotura de la placa y la subsecuente exposición de los componentes de la matriz extracelular permiten que las plaquetas se activen y desencadenen la formación del trombo, lo cual es frecuente en etapas avanzadas de esta patología; por lo tanto, las plaquetas no son simples mediadores de la hemostasia y la trombosis, sino que son un factor clave en el proceso inflamatorio característico de esta enfermedad'.

\section{Lipoproteínas de baja densidad y su relación con la ateroesclerosis}

Las LDL son consideradas como uno de los principales detonantes de la ateroesclerosis. Estos complejos macromoleculares formados por lípidos y proteínas participan en el metabolismo de los lípidos. Los estudios in vitro han mostrado que, independientemente de su concentración, las LDL en su forma nativa no se acumulan en los macrófagos; estas deben oxidarse primero para poder ser reconocidas por los receptores scavengers de dichos macrófagos para luego ser internalizadas por ellos. La oxidación de las LDL puede llevarse a cabo dentro o fuera de la capa íntima de los vasos sanguíneos ${ }^{4}$. En la circulación, las LDL pueden interacionar con radicales libres, lo cual conduce a su oxidación, misma que si se extiende por mucho tiempo da lugar a la formación de hidroperóxidos de ésteres de colesterilo, que se han propuesto como biomarcadores de estrés oxidativo. Las LDL, mediante transitosis, pueden pasar a la capa íntima del endotelio y oxidarse por diversos mecanismos:

- Oxidación mediada por células endoteliales, células del músculo liso o macrófagos, entre otras.

- Oxidación por peroxinitrito, el cual proviene del óxido nítrico (NO) que ha sido inactivado por el anión superóxido.

- Oxidación por proteoglicanos, que son abundantes en la matriz extracelular, sobre todo el sulfato de condroitina que puede unirse a la apolipoproteína B100 de las LDL.

- Oxidación por iones metálicos, como hierro o cobre, que reaccionan con enzimas como la mieloperoxidasa y la lipoxigenasa ${ }^{5}$.
- Oxidación por pH, el cual se ha descrito como ligeramente ácido en el centro de las lesiones ateroescleróticas, lo que favorece que las células endoteliales lleven a cabo la glucólisis anaerobia generando ácido láctico y provocando así la acidificación del espacio extracelular.

- Oxidación por glicación no enzimática de las LDL en la apolipoproteína $B$, en particular en el aminoácido de lisina.

Estos procesos favorecen la internalización de las LDL a los macrófagos y la polarización de estos hacia células espumosas, que son clave en el desarrollo de la ateroesclerosis ${ }^{4,6}$.

En la actualidad, las concentraciones de LDL ( $\geq 132 \mathrm{mg} / \mathrm{dl}$ ) se utilizan como marcador de riesgo de padecer enfermedad cardiaca coronaria ${ }^{7}$. Los ácidos grasos procesados en el hígado (oxidados) son transportados por las lipoproteínas de muy baja densidad, también referidas como lipoproteínas ricas en triglicéridos, que a su vez intercambian estos triglicéridos con las lipoproteínas de alta densidad (HDL) y las LDL, lo que genera que ambas lipoproteínas se tornen ricas en triglicéridos para después perderlos en el hígado por la enzima lipoproteína lipasa hepática. Esto las convierte en LDL más pequeñas, más densas y más aterogénicas, mientras que las HDL, al también haberse tornado más pequeñas, pierden su capacidad protectora y además son catabolizadas más rápido en el riñón, lo que genera la baja de su concentración. Lo anterior conlleva que, aun cuando se mantengan las concentraciones adecuadas de LDL, haya un aumento del riesgo proaterogénico, causado por el tamaño y la pérdida de contenido de estas lipoproteínas, y por otra parte las concentraciones de triglicéridos aumentan en relación inversamente proporcional al diámetro de las partículas de $\mathrm{LDL}^{7-10}$.

\section{Adhesión de las plaquetas al endotelio durante la ateroesclerosis}

El tejido vascular es de suma importancia en el ser humano y es más que una capa de células que recubren los vasos; se considera un órgano metabólicamente activo que desempeña diversas funciones según el estímulo recibido ${ }^{11}$. Las plaquetas circulantes no solo participan en la rotura de la placa ateroesclerótica, sino que también potencian y modulan reacciones inflamatorias. De acuerdo con lo anterior, las plaquetas pueden adherirse a la pared de los vasos sanguíneos dañados 0 al endotelio activado 0 


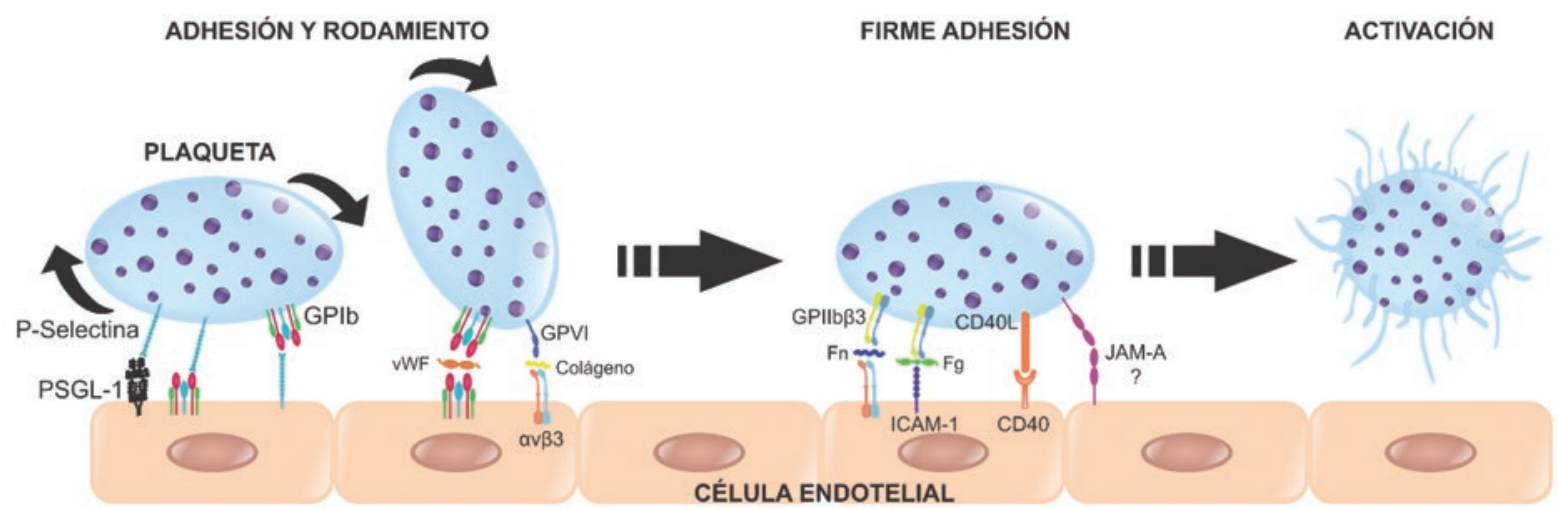

Figura 1. Activación plaquetaria. La activación de plaquetas es un proceso multietapa que comprende el acercamiento de estas al endotelio, la adhesión, el rodamiento y la firme adhesión. Durante dicho proceso, las plaquetas interactúan con las células endoteliales. La primera interacción es a través de la P-selectina en la plaqueta y la PSGL-1 en la célula endotelial, seguida de la interacción de la P-selectina de la célula endotelial y la GPIb de la plaqueta. El rodamiento requiere la unión de GPIb con GPIb en la plaqueta y la célula endotelial, mediada por el factor de Von Willebrand. La integrina GPVI de la plaqueta interactúa con la integrina $\alpha$ V 33 de la célula endotelial, desencadenando a su vez en la plaqueta la activación de la integrina GPIIbß3, que interacciona a través de la fibronectina con $\alpha$ V33 de la célula endotelial. También la ICAM-1 de la célula endotelial, a través del fibrinógeno, se une a la integrina GPIlbß3 de la plaqueta. Finalmente, el CD4OL de la plaqueta se une con el CD40 de la célula endotelial, promoviendo de esta forma la firme adhesión y la subsecuente activación plaquetaria. Fg: fibrinógeno; Fn: fibronectina; PSGL-1: ligando de P-selectina 1; vWF: factor de Von Willebrand.

disfuncional, promoviendo el reclutamiento de células involucradas en la inmunidad innata y adaptativa ${ }^{1,12}$. El endotelio normalmente mantiene un estado antitrombótico por la liberación de diversas sustancias, como NO, prostaciclina y ciclooxigenasa 2 (COX-2); sin embargo, un endotelio activo cambia su estado a protrombótico aumentado la liberación de difosfato de adenosina (ADP) y de factor de Von Willebrand, e incrementando la expresión de factor tisular (TF), así como de diversas moléculas de adhesión, como las moléculas de adherencia intercelular (ICAM), las moléculas de adhesión a células vasculares (VCAM) y las proteínas quimiotácticas de monocitos 1 (MCP-1), entre otras ${ }^{12,13}$. La deposición de LDL nativa u oxidada en la capa íntima de las arterias promueve la activación del endotelio, lo que origina que las plaquetas circulantes se unan y activen ${ }^{14}$. Las plaquetas activadas independientemente del endotelio pueden unirse a este; por ejemplo, se sabe que las LDL oxidadas (LDLox) de la circulación se unen al receptor scavenger (CD36) de la plaqueta, el cual activa a NOX-2 (NADPH Oxidase Isoform 2) promoviendo la activación de estas y su consecuente unión al endotelio ${ }^{15}$.

La P-selectina es una molécula de adhesión indispensable para la unión de las plaquetas al endotelio a través del ligando de P-selectina (PSGL-1) o con el receptor del factor de Von Willebrand glicoproteína Ib (GPIb) presentes en el endotelio; a su vez, las plaquetas, mediante el mismo receptor GPIb, se unen a la P-selectina del endotelio, permitiendo la adhesión y el rodamiento de estas sobre la capa endotelial. Bajo altas fuerzas de estrés, las plaquetas activadas también pueden adherirse y rodar utilizando el mismo mecanismo ${ }^{13}$. Se ha observado que el receptor de colágeno GPVI, que se localiza en la superficie plaquetaria, se une al colágeno expuesto en la matriz subendotelial o al colágeno soluble, y este a su vez es reconocido por la integrina $\alpha v \beta 3$ de la célula endotelial, lo que permite la adhesión y el rodamiento de las plaquetas sobre el endotelio ${ }^{13}$. Así mismo, el receptor GPIb que reconoce al factor de Von Willebrand se une a su receptor expresado en células endoteliales, lo cual también permite el rodamiento de las plaquetas sobre el endotelio (Fig. 1) ${ }^{13,16}$.

Así mismo, los eventos antes descritos desencadenan la activación de las integrinas $\alpha$ llb $\beta 3$ y $\alpha$ ll $\beta 1$, lo que genera agregación plaquetaria ${ }^{17}$. La integrina $\alpha$ llbß3 es capaz de unirse al fibrinógeno unido a ICAM-1 y a la fibronectina unida a $\alpha \mathrm{v} \beta 3$ en la célula endotelial, contribuyendo así a la adhesión estable ${ }^{18}$. La $\alpha$ ll $\beta 1$ puede unirse al colágeno que es reconocido por la integrina $\alpha v \beta 3$ en la célula endotelial, lo que coopera a la adhesión estable, permitiendo que la plaquetas se activen (Fig. 1) 13,19.

Otra proteína relacionada con la adhesión y la activación plaquetaria es el receptor 2 parecido a lectina tipo $C$, que activa vías de señalización que involucran a Src y PI3K, las cuales se ha observado que también se activan por los receptores antes mencionados (GPIb y GPVI) ${ }^{20}$.

Otra molécula que participa en la adhesión de las plaquetas al endotelio es el ligando de CD40 (CD40L 
o CD154), el cual, debido a la activación plaquetaria, forma complejos triméricos que se unen a su receptor CD40 de la célula endotelial, e incluso se ha descrito que pueden unirse a la integrina $\alpha$ llb $\beta 3$ de otras plaquetas, lo que permite la formación de agregados. También se ha observado que el CD40L de las plaquetas se fragmenta y solubiliza formando CD40L soluble (sCD40L o sCD154), promoviendo la activación y la agregación de otras plaquetas y activando a las células endoteliales, que aumentan la expresión de moléculas de adhesión y la liberación de interleucinas y quimiocinas, generando también adhesión plaquetaria $^{21}$ (Fig. 1).

La molécula de adhesión ocluyente A (JAM-A) de la plaqueta se creía que se unía a otra molécula JAM-A en la célula endotelial, y esto generaba activación plaquetaria, pero se ha observado que al unirse la JAM-A de la plaqueta a la JAM-A de otra plaqueta se genera inactivación de la integrina $\alpha$ llb $\beta 3$, inhibiendo la agregación plaquetaria ${ }^{20}$.

Todas estas interacciones expuestas son solo algunas de las que pueden ocurrir durante la adhesión plaqueta-plaqueta y plaqueta-endotelio, cuya consecuencia es la activación plaquetaria con el fin de promover la formación del trombo o ejercer su función inmunitaria.

\section{Mecanismos de activación plaquetaria}

El factor de Von Willebrand se une a GPIb $\alpha$, que forma parte del complejo receptor GPIb-IX-V de la plaqueta, induciendo que miembros de la familia de las cinasas Src fosforilen los motivos ITAM de GPIb $\alpha$, lo que a su vez atrae a SYK (otro miembro de la familia Src), que fosforila a LAT ${ }^{22}$. La LAT fosforilada recluta a PI3K, que induce la activación de PLCロ2 y PKC, las cuales disparan la liberación de calcio del retículo endoplásmico ${ }^{23}$. El aumento del calcio induce la activación de Rap-1b, y la Rap-1b activada atrae a la talina, produciendo la activación de varias integrinas y en consecuencia la agregación plaquetaria ${ }^{24}$. La siguiente etapa de activación, que podemos llamarla de «amplificación», es dependiente de los agonistas derivados de los gránulos plaquetarios, tales como ADP, tromboxano A2 ( $\left.\mathrm{TxA}_{2}\right)$, trombina, prostaciclina, serotonina 0 adrenalina, por mencionar algunos ${ }^{23}$. Dichos agonistas activan a los receptores acoplados a proteínas G, como P2Y1 y P2Y12 (receptores de ADP), PAR1 y PAR4 (receptores de trombina), TP (receptor de $\operatorname{TxA}_{2}$ ), 5-hidroxitriptamina (receptor de serotonina) y EP3 (receptor de prostaglandina E2) ${ }^{25}$. Estos receptores permiten la activación de PLC $\beta$, que al igual que PLC $\beta 2$, tiene por objeto activar a PKC promoviendo el aumento intracelular de calcio y la activación de Rho, lo cual resulta en la activación de las plaquetas y la consecuente secreción de gránulos, aumentando la agregación de estas ${ }^{23,26}$.

\section{El endotelio como órgano proateroesclerótico}

El endotelio es considerado un órgano metabólicamente activo (autocrino y paracrino), que desempeña una función crítica en la regulación fisiológica del tono vascular, la adhesión, la migración celular y la resistencia a la trombosis, entre otras, todo ello en función del estímulo que recibe. Estas funciones las lleva a cabo mediante la liberación o la expresión de moléculas de adhesión, factores de crecimiento, compuestos antioxidantes y agentes vasodilatadores o vasoconstrictores. Para que se establezca la ateroesclerosis es necesario que el endotelio se active y se vuelva disfuncional. La activación se refiere a la capacidad de las células endoteliales para realizar nuevas funciones sin evidencia de lesión o disfunción celular. Así mismo, la disfunción endotelial surge al mantener las respuestas adaptativas de forma excesiva, sostenida y fuera de lugar, lo que altera la homeostasis vascular, predisponiendo así la pared vascular a la vasoconstricción, la adhesión leucocitaria, la activación plaquetaria, el estrés oxidativo, la trombosis, la coagulación o la inflamación, y favoreciendo el establecimiento de diversas patologías ${ }^{12,27,28}$.

En las células, en general, el NO es sintetizado a partir de L-arginina por un grupo de enzimas denominadas óxido nítrico sintetasas (NOS); en la célula endotelial, este proceso lo lleva acabo la óxido nítrico sintetasa endotelial (eNOS). En la ateroesclerosis, las concentraciones aumentadas y sostenidas de LDL en contacto con especies reactivas del oxígeno (ROS), sobre todo $\mathrm{O}_{2}$, permite su oxidación. La hiperlipidemia origina una regulación positiva de la NADPH oxidasa de la célula endotelial, lo que a su vez genera más ROS $^{27}$. El aumento de este $\mathrm{O}_{2}$ no se puede inactivar por la superóxido dismutasa (SOD) y reacciona con el NO dando lugar a la formación de peroxinitrito, que a su vez es capaz de desestabilizar a la eNOS. Por otra parte, la dimetil arginina asimétrica (ADMA) compite con la L-arginina por el sitio de unión de eNOS, inhibiéndola ${ }^{29}$. También la LDLox aumenta la síntesis de caveolina-1, una proteína integral de membrana que igualmente inhibe a eNOS ${ }^{30}$. La inhibición de la eNOS 

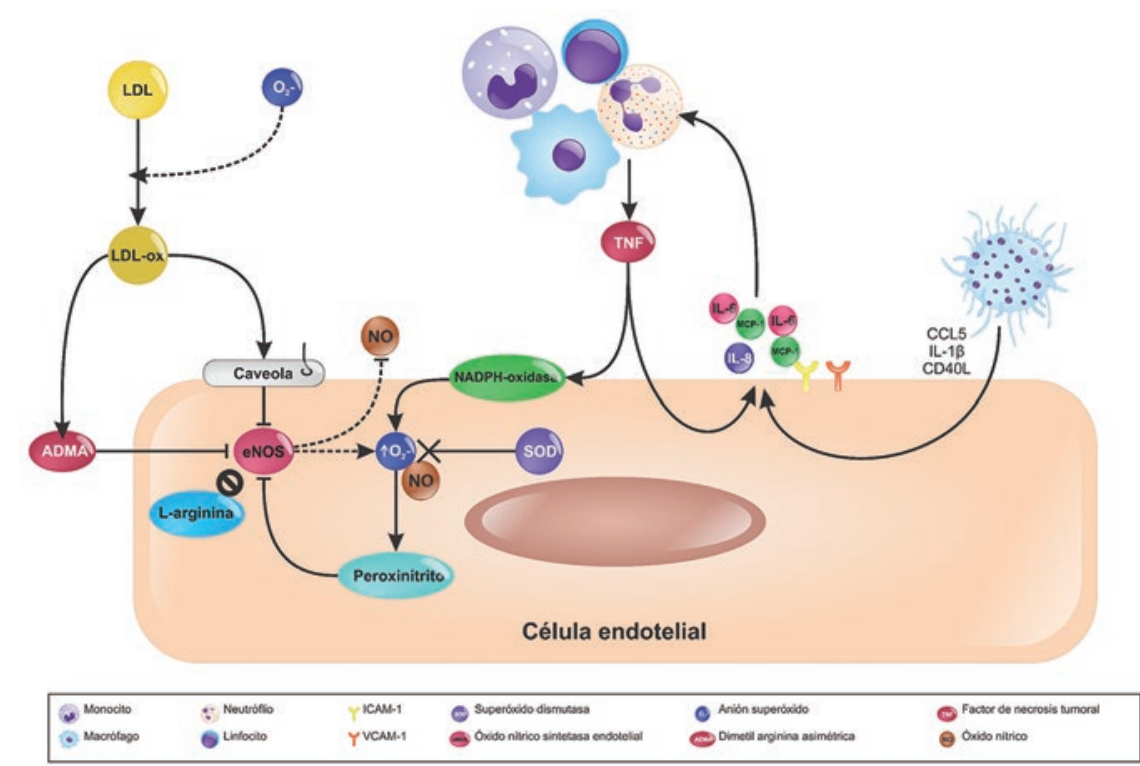

Figura 2. Disfunción endotelial en la ateroesclerosis. El aumento del anión superóxido $\left(O_{2}\right)$ interacciona con las $L D L$ favoreciendo su oxidación. Las LDLox promueven un aumento de ADMA en sangre; este ADMA es un inhibidor competitivo de la eNOS, lo que conlleva la disminución en la producción de NO por la célula endotelial. Por otro lado, las LDLox favorecen la síntesis de caveolas en la célula endotelial, inhibiendo también a la eNOS. Aunado a esto, la estimulación positiva de la NADPH-oxidasa por el TNF secretado por células inflamatorias conduce a la sobreproducción del anión $\mathrm{O}_{2}$, lo que impide que la enzima $\mathrm{SOD}$ inactive a dicho $\mathrm{O}_{2}$ e interaccione con el NO dentro de la célula endotelial, dando lugar a la formación de peroxinitritos que inhiben a la eNOS. En conjunto con lo anterior, las plaquetas, mediante la secreción de CCL5, IL-1 $1 \beta$ y CD40L, pueden aumentar la expresión de moléculas de adhesión y la secreción de citocinas por parte de las células endoteliales, que actúan promoviendo el reclutamiento de células del sistema inflamatorio. ADMA: dimetil arginina asimétrica; eNOS: óxido nítrico sintetasa endotelial; LDL: lipoproteínas de baja densidad; NO: óxido nítrico; SOD: superóxido dismutasa; TNF: factor de necrosis tumoral.

trae como resultado un aumento de ROS (sobre todo $\mathrm{O}_{2}$ ) y una disminución del NO, lo que favorece la activación y la agregación plaquetaria (Fig. 2) ${ }^{30}$. Al generarse estrés oxidativo, este induce la desviación del estado redox normal hacia un ambiente oxidativo. El estado redox es el ambiente químico concerniente al número de equivalentes reductores disponibles, y uno de los principales es el sistema NADH/NAD ${ }^{+31-33}$.

La adhesión de las plaquetas al endotelio promueve que la plaqueta libere la quimiocina CCL5 (RANTES) y CD40L soluble, así como la expresión de CD40L, lo que conduce a la unión de las plaquetas a las células endoteliales, induciendo un aumento en la expresión de moléculas de adhesión y la liberación de citocinas y quimiocinas por la célula endotelial ${ }^{21}$. De igual forma, la liberación de interleucina (IL) $1 \beta$ por las plaquetas induce que las células endoteliales liberen IL-6, IL-8, ICAM y MCP-1, entre otras, lo que también contribuye a su interacción con células inflamatorias (Fig. 2) ${ }^{34}$.

En etapas más avanzadas de la ateroesclerosis, el proceso inflamatorio en el que participan células de la inmunidad innata y adaptativa, como neutrófilos, macrófagos, células dendríticas y linfocitos, entre otros, genera un entorno rico en citocinas, que promueve la activación y la disfunción endotelial, y la unión y la activación de plaquetas al endotelio ${ }^{34}$. Así mismo, se ha observado que el estrés oxidativo amplifica la respuesta inflamatoria por parte de las células endoteliales que reclutan monocitos, linfocitos y neutrófilos, los cuales secretan citocinas como el factor de necrosis tumoral alfa (TNF- $\alpha$ ), el cual, en la célula endotelial, puede regular positivamente a la NADPH oxidasa y negativamente a la eNOS, para de esta manera promover tanto la disfunción endotelial como el aumento de la expresión de citocinas, quimiocinas y moléculas de adhesión ${ }^{27}$.

Las lesiones ateroescleróticas avanzadas expresan un componente importante, denominado activador del plasminógeno tipo urocinasa (UPA), que es una proteasa en serina involucrada en la conversión del plasminógeno a plasmina y en el remodelado vascular ${ }^{35}$. Este UPA es expresado por las células endoteliales presentes en dichas lesiones, al igual que por macrófagos $^{36}$. El UPA puede ser escindido en varios fragmentos biológicamente activos: fragmento amino terminal, dominio kringle y fragmento carboxi terminal, cada uno con propiedades únicas ${ }^{37}$. Por ejemplo, el fragmento amino terminal, al unirse al receptor del activador del plasminógeno tipo urocinasa (u-PARI), 
es capaz de inducir la migración de células del músculo liso vascular ${ }^{36}$, lo que desencadena la activación de diversas vías de señalización involucradas en la migración y la proliferación celulares, como MAPK y JAK-STAT ${ }^{38}$. Por otra parte, el uPA proveniente de células endoteliales de la zona de lesión y de células espumosas puede escindir, además del plasminógeno, otras proteínas de la matriz extracelular, degradar fibrina y activar a las metaloproteinasas (MMP), entre ellas la MMP-9 ${ }^{39}$. También el uPA promueve la formación de plasmina, la cual activa a la MMP-9 que degrada a la matriz extracelular ocasionando que la placa ateroesclerótica se torne vulnerable ${ }^{40-42}$. Por lo antes expuesto, se propone que el sistema uPA media la progresión de la ateroesclerosis ${ }^{43}$.

\section{Interacción de plaquetas y leucocitos}

Al igual que la adhesión plaquetaria al endotelio es mediada por la P-Selectina, la adhesión leucocitaria al endotelio y la formación de agregados plaqueta-leucocito se lleva a cabo por la interacción de la P-selectina con su ligando (PSGL-1) ${ }^{12}$. Sin embargo, se ha visto que los polimorfonucleares, en especial los neutrófilos, al secretar CCL5, y este al unirse a sus receptores CCR1 y CCR5, permiten que ingresen a la capa íntima de las arterias y liberen su contenido, como la azurocidina, que puede actuar sobre el endotelio promoviendo el aumento de expresión de moléculas de adhesión como ICAM-1, VCAM y E-selectina, catepsina G y CAMP (LL37), que promueven la atracción de monocitos hacia este ${ }^{44}$. Se ha observado que los neutrófilos pueden formar agregados plaqueta-neutrófilo, y estos responden a la LDLox aumentando su capacidad de transmigración hacia la capa íntima ${ }^{45}$.

El factor plaquetario 4, también llamado CXCL4, es una de las quimiocinas más abundantes presentes en los gránulos alfa de las plaquetas. Este CXCL4, junto con CCL5, se ha descrito que promueve la adhesión de monocitos al endotelio ${ }^{44}$. El CXCL4 promueve la polarización de macrófagos hacia un fenotipo denominado M4, que se caracteriza por tener baja capacidad fagocítica y alta expresión de transportadores de colesterol ${ }^{46}$.

En la formación de agregados monocito-plaqueta participan la PSGL-1/P-selectina y CD40/CD40L. Esta interacción provoca en el monocito la activación del factor nuclear kappa B (NF-kB), lo que a su vez induce un aumento de la expresión de proteínas inflamatorias, como MCP-1, TNF- $\alpha$, IL-8 y Prostaglandina E2 (PGE2) ${ }^{47}$. La formación de agregados monocito-plaqueta se considera un marcador de activación plaquetaria con mayor valor predictivo incluso que la presencia de citocinas inflamatorias ${ }^{48}$.

Al unirse las plaquetas al endotelio por vía CD40L/ CD40 se promueve el aumento de moléculas de adhesión, como ICAM-1 y VCAM-1, en la célula endotelial, así como la liberación de la quimiocina CCL2, lo que provoca el reclutamiento de linfocitos. La unión del linfocito a las plaquetas mediante PSGL1/P-selectina desencadena en el linfocito la activación de la integrina $\alpha \mathrm{L}$, provocando la adhesión de este a las células endoteliales mediante ICAM-149,50. Las plaquetas también promueven la adhesión de linfocitos $T$ cooperadores a la matriz subendotelial dependiente de P-selectina y CD40L. También se ha documentado que, al unirse las plaquetas a los linfocitos B a través de CD40L/CD40, promueven en estos tanto su diferenciación como el recambio de clase de las inmunoglobulinas ${ }^{49}$.

Además, se ha descrito que la interacción de las células dendríticas con las plaquetas contribuye al desarrollo de la ateroesclerosis; por ejemplo, evidencias in vitro proponen que las plaquetas pueden reclutar células dendríticas mediante la interacción JAM-C/Mac-1 (antígeno-1 de macrófagos), promoviendo la fagocitosis de las plaquetas y la posterior muerte de las células dendríticas, induciendo de esta forma un ambiente inflamatorio ${ }^{51}$. Las plaquetas también pueden interactuar con células dendríticas por la unión CD40L/CD40, promoviendo la maduración y la diferenciación de las células dendríticas, además de estimular la liberación de citocinas y quimiocinas por parte de estas ${ }^{14,47}$.

\section{Micropartículas derivadas de plaquetas}

La mayoría de las células liberan vesículas extracelulares que derivan de su membrana; estas pueden contener diversas biomoléculas, como proteínas, lípidos, hidratos de carbono o ácidos nucleicos, entre otros, y tienen un impacto en células adyacentes o distantes. Las vesículas extracelulares fueron observadas originalmente por Chargaff y West, en 1946, como partículas procoagulantes derivadas de plaquetas; más adelante, en 1967, fueron referidas por Wolf como polvo plaquetario ${ }^{52}$. Estas vesículas contienen membrana proveniente de la célula de la cual se liberaron, y se clasifican de acuerdo con su función y origen celular (tolerosomas, prostatosomas, cardiosomas, vexosomas, etc.) o según su tamaño (exosomas de 40-120 nm; ectosomas, micropartículas o microvesículas de 100-1000 nm; cuerpos apoptóticos de 500-2000 nm). 


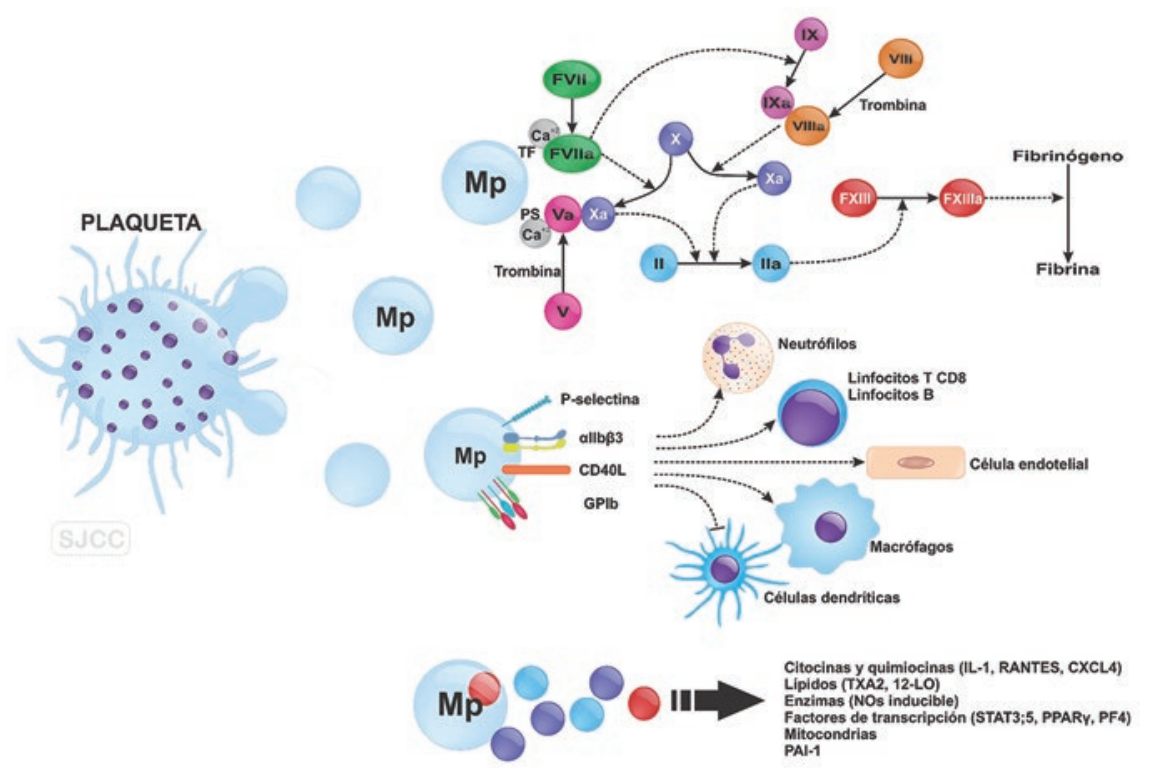

Figura 3. Las micropartículas derivadas de plaquetas poseen fosfolípidos aniónicos que permiten el ensamblaje del complejo de iniciación de la coagulación (TF $+\mathrm{FVlla}+\mathrm{Ca}^{+2}$ ), además del complejo protrombinasa $\left(\mathrm{FVa}+\mathrm{FXa}+\mathrm{Ca}^{+2}\right)$, lo cual conduce a un aumento de la trombosis. Las micropartículas también contienen integrinas, ligandos y moléculas de adhesión que permiten formar agregados con los leucocitos. Estos agregados de micropartículas y leucocitos interactúan con las células dendríticas y las células epiteliales. Por otra parte, estas micropartículas contienen citocinas y quimiocinas, otras moléculas derivadas de lípidos ( $T X A_{2}$ y 12-LO), enzimas y factores de crecimiento, entre otros, lo cual favorece el proceso inflamatorio. 12-LO: 12-lipoxigenasa; MP: micropartículas; PS: fosfatidilserina; TF: factor tisular; TXA $A_{2}$ tromboxano A2.

Las microvesículas o micropartículas derivadas de plaquetas son las más abundantes en la sangre humana y las más ampliamente estudiadas ${ }^{53}$. Estas micropartículas, en condiciones fisiológicas, tienen un papel en el mantenimiento de la homeostasis, pero bajo ciertos estímulos, como cáncer, enfermedades cardiovasculares, infección o inflamación, entre muchos otros, su número aumenta y se produce una desregulación de diversos sistemas, entre ellos el linfático y el de coagulación ${ }^{54}$. Estas micropartículas derivadas de plaquetas pueden contener caspasas ( 3 y 9 ), factores de transcripción (NF-kB, STAT, SOX), ligandos (CD40L, CXCL4), citocinas (IL-1ß), quimiocinas (CCL5, CXCL7, CXCL4), factores de crecimiento Factor de crecimiento del endotelio vascular [VEGF], Factor de crecimiento derivado de plaquetas [PDGF], ácidos nucleicos (miRNAs, mR$\mathrm{NAs}$ ), mediadores lipídicos ( $\mathrm{TxA}_{2}$, ácido araquidónico), enzimas (COX-1, heparanasa) y restos de mitocondrias $^{55}$. También estas micropartículas pueden ser procoagulantes debido a que su membrana es asimétrica en cuanto al contenido de fosfolípidos, como fosfatidilcolina y fosfatidilserina ${ }^{55}$. La fosfatidilserina expuesta en las micropartículas provee una superficie cargada negativamente, lo cual es requerido por los complejos protrombinasa y tenasa extrínsecos formados como parte del proceso de coagulación. Como se sabe, la coagulación inicia con la exposición del TF y la subsecuente unión de este al factor VII para formar el complejo tenasa extrínseco (TF-VIla), el cual actúa sobre el factor $X$ activándolo. Este factor $X a$ se une al factor Va en presencia de $\mathrm{Ca}^{+2}$ para formar el complejo protrombinasa ( $F V a-F X a)$. A su vez, el factor $X$ también es activado por el complejo tenasa intrínseco (FVIIla-FIXa) en presencia de $\mathrm{Ca}^{+2}$, y dicho factor $\mathrm{Xa}$ igualmente participa en la generación del complejo protrombinasa ${ }^{55,56}$. Estas mismas micropartículas derivadas de plaquetas también secretan inhibidor del activador del plasminógeno (PAl-1), lo que inhibe el sistema fibrinolítico; esto es importante sobre todo en etapas avanzadas de la ateroesclerosis, cuando la placa se vuelve susceptible a la rotura desencadenando el proceso de coagulación (Fig. 3) ${ }^{57}$.

Debido a su contenido de caspasas, las micropartículas derivadas de plaquetas promueven la apoptosis de células endoteliales y leucocitos, y esto favorece que en las placas trombóticas haya un aumento de micropartículas tanto derivadas de plaquetas como de leucocitos y células endoteliales, mismas que se acumulan y potencian la formación del trombo y la ocurrencia de eventos inflamatorios ${ }^{58}$.

Las micropartículas derivadas de plaquetas pueden reclutar leucocitos, ya que poseen integrinas como $\alpha$ llb33, GPIb, GPIX (CD42a) y GPIIlb (CD36), y moléculas de adhesión como P-selectina y PECAM-1, 


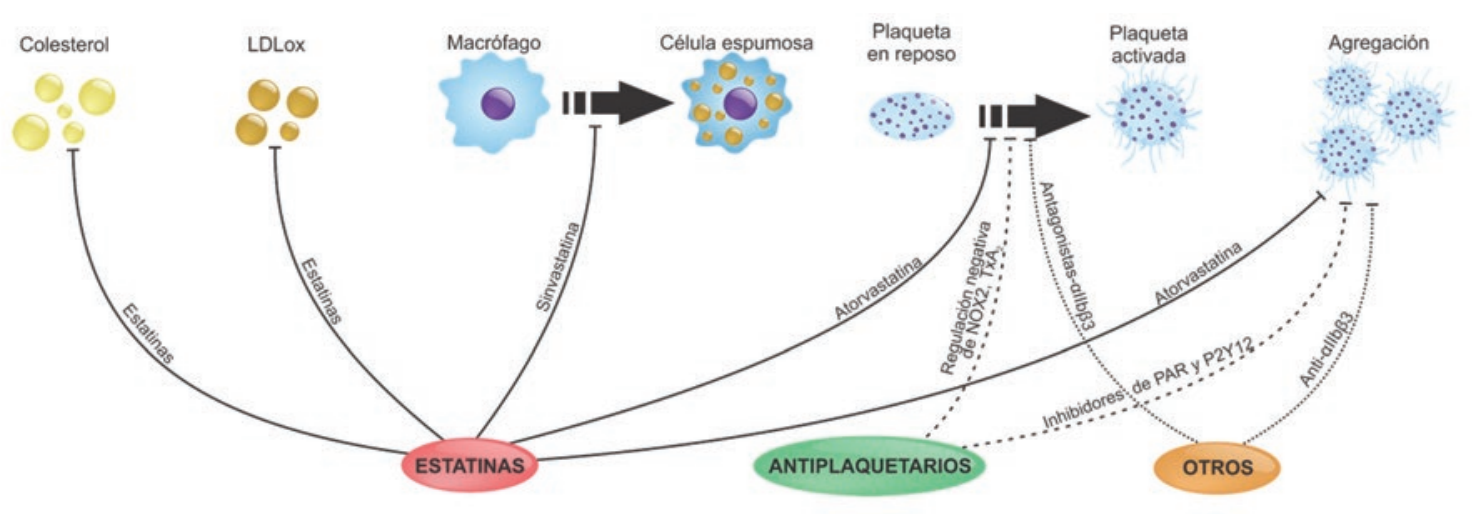

Figura 4. Tratamiento de la ateroesclerosis. Las estatinas inhiben la interacción de las LDLox con los macrófagos, lo cual impide la formación de células espumosas, y también bloquean la activación y la agregación plaquetaria. Los fármacos antiplaquetarios actúan inhibiendo la activación y la agregación plaquetaria mediante el bloqueo de diversos receptores a ADP, trombina y $T x A_{2}$; además, algunos son capaces de inhibir la liberación de CD40L soluble y de IL-6, lo que potencia aún más su efecto antiplaquetario. Se han usado anticuerpos monoclonales como inhibidores de las integrinas $\alpha$ llb $\beta 3$. LDLox: lipoproteínas de baja densidad oxidadas; TXA $A_{2}$ tromboxano $A 2$.

JAM-A, etc. Esto genera la adhesión de leucocitos a las micropartículas, formando agregados micropartícula-leucocito ${ }^{55}$. Estas micropartículas, al contener citocinas y quimiocinas, como IL-1 $\beta$, RANTES y CXCL4, reclutan leucocitos hacia las células endoteliales, promoviendo la inflamación y la ateroesclerosis. Además, las micropartículas contienen factor activador de plaquetas, que permite la activación de neutrófilos y macrófagos (Fig. 3) ) $^{55}$. Asi mismo, la LDLox puede interactuar con el receptor CD36 en la plaqueta, generando su activación y la subsecuente generación de micropartículas ${ }^{59}$.

\section{Enfoques terapéuticos}

Actualmente las estatinas son medicamentos de primera línea utilizados para el tratamiento de las concentraciones elevadas de lípidos plasmáticos, e incluso en la prevención primaria de enfermedades coronarias. Las estatinas actúan inhibiendo a la enzima 3-hidroxi 3 metilglutaril coenzima A (HMG-CoA) reductasa, la cual es la primera y principal enzima de la biosíntesis del colesterol; de esta manera se impide la generación de precursores de colesterol en el hígado y la reducción del colesterol LDL (considerado como uno de los principales factores de riesgo cardiovascular), ya que al reducir esta enzima se aumenta el número de receptores hepáticos para LDL (Fig. 4) ${ }^{60}$. Por otro lado, las estatinas tienen un efecto pleiotrópico muy amplio, pues pueden tener efectos antitrombóticos directos, como la simvastatina, que impide la interacción de la LDLox con monocitos y al mismo tiempo disminuye la expresión de TF inducido por LDLox sin causar un cambio en las concentraciones de colesterol ${ }^{61}$. A su vez, diversas estatinas se han implicado en disminuir la expresión del TF, incrementar la generación de trombomodulina e inhibir al factor $V$, entre otras acciones, lo que evita su activación y agregación. Además, se ha visto que la atorvastatina puede inhibir la activación plaquetaria directamente, mediante regulación negativa de la activación de la COX-162. Otras vías involucradas en inhibir la activación plaquetaria son la disminución del estrés oxidativo mediante la regulación negativa de NOX2 y de TxA $A_{2}$ y la liberación de NO; esto, por una parte, evita la activación y por ende la liberación de citocinas y quimiocinas, como CXCL4 y CXCL7, y por otro lado, la reducción del estrés oxidativo disminuye la capacidad de las LDL de ser oxidadas ${ }^{62,63}$. En conjunto con lo anterior, las estatinas pueden inhibir la fase de amplificación plaquetaria al inhibir la activación del receptor para trombina (PAR-4) ${ }^{64}$. Sumado a lo dicho, se ha demostrado que las estatinas (rosuvastatina) pueden disminuir el volumen plaquetario medio (VPM), el cual se considera como un posible marcador determinante de activación plaquetaria, debido a que las plaquetas circulantes en reposo tienen forma discoide, pero al activarse cambian de forma, ya que desarrollan filopodios y lamelipodios que generan un aumento de su superficie, mismo que se ve reflejado en un mayor volumen plaquetario medio ${ }^{65}$.

Otros medicamentos que se usan ampliamente como tratamiento de las enfermedades coronarias son los antiplaquetarios, entre los que destacan tres: clopidogrel, prasugrel y ticagrelor. Los tres son inhibidores del receptor plaquetario de ADP (P2Y12), pero los dos últimos han demostrados ser más potentes y de actuación más rápida que el clopidogrel (Fig. 4) ${ }^{66}$. 
El clopidogrel se usa de manera estándar en combinación con aspirina como tratamiento antiagregante para reducir los eventos isquémicos en pacientes con enfermedad aterotrombótica; el clopidogrel, como ya se mencionó, es un inhibidor del receptor para ADP, mientras que la aspirina es un inhibidor irreversible de la COX-1, lo que resulta en una disminución de la producción de prostaglandinas y de $\mathrm{TxA}_{2}$, y con ello una reducción de la activación y la agregación plaquetaria ${ }^{67}$.

También se han desarrollado inhibidores del receptor para la trombina PAR-1, como vorapaxar y atopaxar; este último, además de inhibir dicho receptor en modelos múridos, ha demostrado disminuir la liberación de moléculas proinflamatorias, como CD40L soluble e IL-6, y la expresión de P-selectina. En humanos también demostró ser capaz de inhibir tanto la liberación de CD40L como el aumento de expresión de las moléculas de adhesión en la célula endotelial ${ }^{68}$.

El ticagrelor tiene un modo de acción único y diferente a los anteriores: no requiere activación metabólica para la actividad antiplaquetaria (a diferencia del clopidogrel y el prasugrel, que tienen un inicio de acción retardado al requerir activación metabólica) y se une de manera reversible a P2Y12, lo que permite la recuperación de la función plaquetaria más rápido (a diferencia del clopidogrel, que se une de manera irreversible a P2Y12) ${ }^{69}$.

De acuerdo con lo antes descrito, los efectos de los antiplaquetarios se basan en bloquear uno u otro receptor para los agonistas plaquetarios; sin embargo, como ya se ha comentado, las vías de señalización que cada receptor activa corriente abajo en algunos casos convergen entre ellas, mientras que en otros no, y esto es lo que lleva a utilizar terapias duales para tratar de abarcar la mayor cantidad de proteínas relacionadas con dichas vías y obtener el efecto esperado. A su vez, es necesario puntualizar que estos medicamentos tienen efectos permanentes, lo que podría generar algunos efectos adversos para ciertos pacientes. Por ejemplo, la terapia dual con aspirina y clopidogrel presenta la limitante de que el clopidogrel es un antiplaquetario irreversible, lo cual puede causar un riesgo significativo de hemorragia en pacientes que requieren cirugía y no han suspendido el tratamiento por 5-7 días. Otro efecto es la variabilidad de la inhibición plaquetaria por el clopidogrel, que explica por qué algunos pacientes, aun con dosis sostenidas de este fármaco, presentan reactividad plaquetaria elevada $^{67}$. Debido a lo anterior han surgido nuevas versiones de estos bloqueadores de P2Y12 (receptor de ADP), como el cangrelor, que es un inhibidor directo y reversible de este receptor, y el elinogrel, que también actúa directamente sobre P2Y12 y es un inhibidor competitivo y reversible de este mismo receptor, y que al parecer tiene menos efectos secundarios que el clopidogrel ${ }^{70}$. Debido a lo complicado de la fisiología plaquetaria han surgido diversos intentos por mejorar la inhibición de las plaquetas y se ha intentado bloquear ciertas integrinas, como la $\alpha$ llb $\beta 3$, con anticuerpos monoclonales. El abciximab es un anticuerpo quimérico ratón/humano que es capaz de inhibir la agregación plaquetaria al actuar directamente en estas integrinas ${ }^{71}$. La eptifibatida y el tirofibán también son antiagregantes al ser antagonistas de $\alpha$ llbß3. El primero es un heptapéptido cíclico de menos de $1 \mathrm{kDa}$, y un potente inhibidor de la unión del fibrinógeno a las plaquetas. El segundo es un péptido de bajo peso molecular y de corta acción, que en los humanos se une de manera reversible, y al parecer con baja afinidad, a $\alpha$ llb $\beta 3^{72}$. Estos últimos medicamentos no se han estandarizado para uso humano, ya que no alcanzan a tener el efecto deseado en la mayoría de los pacientes y por ello se han relegado.

\section{Conclusión}

La ateroesclerosis es una enfermedad con características trombóticas e inflamatorias. El estudio de la ateroesclerosis en los humanos es limitado y generalmente se obtiene de disecciones de autopsias o de mediciones del aumento de alguna molécula en sangre como respuesta a un estímulo. Las plaquetas, que la mayoría de las veces solo se conocen por su participación en la trombosis, tienen una importante participación tanto en etapas tempranas de la ateroesclerosis como en etapas avanzadas, al haber rotura y una subsecuente exposición de matriz subendotelial. El papel de las plaquetas no se limita a la trombosis o la hemostasia, sino que tienen una participación activa en el proceso inflamatorio, ya que activan células como monocitos, neutrófilos, linfocitos y células dendríticas, entre otras, que favorecen un microambiente inflamatorio que ayuda al progreso de la ateroesclerosis. Las plaquetas tienen la capacidad de formar agregados y secretar citocinas y quimiocinas que actúan tanto sobre las células inflamatorias como el endotelio, promoviendo que este cambie a un estado proinflamatorio y proateroesclerótico. Estos procesos involucran diversas vías de señalización que desencadenan la activación de moléculas de adhesión, integrinas y receptores acoplados a proteínas $\mathrm{G}$. Dichas vías han contribuido a desarrollar terapias 
farmacológicas, pero su complejidad ha impedido el desarrollo de fármacos más efectivos. El tratamiento antiinflamatorio para este padecimiento solo está representado parcialmente por las estatinas. Esto abre la posibilidad de tratar de inhibir o controlar el estado inflamatorio con nuevos esquemas de tratamiento, además del desarrollo de nuevos fármacos antiinflamatorios selectivos para la ateroesclerosis.

\section{Conflicto de intereses}

Los autores de este articulo declaran no tener conflicto de intereses.

\section{Financiamiento}

S.J. Custodio-Chablé fue becario de CONACYT. R.A. Lezama y E. Reyes-Maldonado recibieron apoyo del programa SIP y Beifi del IPN.

\section{Responsabilidades éticas}

Protección de personas y animales. Los autores declaran que para esta investigación no se han realizado experimentos en seres humanos ni en animales.

Confidencialidad de los datos. Los autores declaran que en este artículo no aparecen datos de pacientes.

Derecho a la privacidad y consentimiento informado. Los autores declaran que en este artículo no aparecen datos de pacientes

\section{Bibliografía}

1. Hansson GK, Libby P. The immune response in atherosclerosis: a double-edged sword. Nat Rev Immunol. 2006;6:508-19.

2. Le NA. Lipoprotein-associated oxidative stress: a new twist to the postprandial hypothesis. Int J Mol Sci. 2014;16:401-19.

3. Spence JD. Intestinal microbiome and atherosclerosis. EBioMedicine. 2016;13:17-8

4. Yoshida H, Kisugi R. Mechanisms of LDL oxidation. Clin Chim Acta 2010;411:1875-82.

5. Lee S, Birukov KG, Romanoski CE, Springstead JR, Lusis AJ, Berliner JA. Role of phospholipid oxidation products in atherosclerosis. Circ Res. 2012;111:778-99.

6. Maiolino G, Rossitto G, Caielli P, Bisogni V, Rossi GP, Calò LA. The role of oxidized low-density lipoproteins in atherosclerosis: the myths and the facts. Mediators Inflamm. 2013;2013:1-13.

7. Carmena R. Atherogenic lipoprotein particles in atherosclerosis. Circulation. 2004;109(23 Suppl 1):III-2-7.

8. Nordestgaard BG, Varbo A. Triglycerides and cardiovascular disease. Lancet. 2014;384:626-35.

9. Lawler PR, Akinkuolie AO, Chu AY, Shah SH, Kraus WE, Craig D, et al. Atherogenic lipoprotein determinants of cardiovascular disease and residual risk among individuals with low lowndensity lipoprotein cholesterol. J Am Heart Assoc. 2017:6:1-17.

10. Chapman MJ, Ginsberg HN, Amarenco P, Andreotti F, Borén J, Catapano AL, et al. Triglyceride-rich lipoproteins and high-density lipoprotein cholesterol in patients at high risk of cardiovascular disease: evidence and guidance for management. Eur Heart J. 2011;32:1345-61.

11. McCarron JG, Lee MD, Wilson C. The endothelium solves problems that endothelial cells do not know exist. Trends Pharmacol Sci. 2017;38:322-38.
12. Rajendran $P$, Rengarajan $T$, Thangavel J, Nishigaki $Y$, Sakthisekaran D, Sethi $\mathrm{G}$, et al. The vascular endothelium and human diseases. Int J Biol Sci. 2013;9:1057-69.

13. van Gils JM, Zwaginga JJ, Hordijk PL. Molecular and functional interactions among monocytes, platelets, and endothelial cells and their relevance for cardiovascular diseases. J Leukoc Biol. 2009;85:195-204.

14. Bäck M, Weber C, Lutgens E. Regulation of atherosclerotic plaque inflammation. J Intern Med. 2015;278:462-82.

15. Magwenzi S, Woodward C, Wraith KS, Aburima A, Raslan Z, Jones $\mathrm{H}$, et al. Oxidized LDL activates blood platelets through CD36/NOX2-mediated inhibition of the cGMP/protein kinase G signaling cascade. Blood. 2015;125:2693-703.

16. Canobbio I, Balduini C, Torti M. Signalling through the platelet glycoprotein Ib-V-IX complex. Cell Signal. 2004;16:1329-44.

17. Durrant TN, van den Bosch MT, Hers I. Integrin $\alpha$ Ilb $\beta 3$ outside-in signaling. Blood. 2017;130:1607-19.

18. Lam FW, Vijayan KV, Rumbaut RE. Platelets and their interactions with other immune cells. En: Comprehensive physiology. Hoboken, NJ, USA: John Wiley \& Sons; 2015. p. 1265-80.

19. Madamanchi A, Santoro SA, Zutter MM. $\alpha 2 \beta 1$ Integrin. Adv Exp Med Biol. 2014;819:41-60.

20. Bye AP, Unsworth AJ, Gibbins JM. Platelet signaling: a complex interplay between inhibitory and activatory networks. J Thromb Haemost. 2016; 14:918-30.

21. Michel NA, Zirlik A, Wolf D. CD40L and its receptors in atherothrombosis - an update. Front Cardiovasc Med. 2017;4:1-40.

22. Senis $Y$, Mazharian A, Mori J. Src family kinases: at the forefront of platelet activation. Blood. 2014;124:2013-24.

23. Li Z, Delaney MK, O'Brien KA, Du X. Signaling during platelet adhesion and activation. Arterioscler Thromb Vasc Biol. 2010;30:2341-9.

24. Shattil SJ, Kim C, Ginsberg MH. The final steps of integrin activation: the end game. Nat Rev Mol Cell Biol. 2010;11:288-300.

25. Gurbel PA, Kuliopulos A, Tantry US. G-protein-coupled receptors signaling pathways in new antiplatelet drug development. Arterioscler Thromb Vasc Biol. 2015;35:500-12

26. Estevez B, Du X. New concepts and mechanisms of platelet activation signaling. Physiology. 2017;32:162-77.

27. Mudau M, Genis A, Lochner A, Strijdom H. Endothelial dysfunction: the early predictor of atherosclerosis. Cardiovasc J Afr. 2012;23:222-31.

28. Favero G, Paganelli C, Buffoli B, Rodella LF, Rezzani R. Endothelium and its alterations in cardiovascular diseases: life style intervention. Biomed Res Int. 2014;2014:1-28

29. Shin S, Thapa SK, Fung H-L. Cellular interactions between L-arginine and asymmetric dimethylarginine: transport and metabolism. PLoS One. 2017;12:e0178710.

30. Förstermann U, Sessa WC. Nitric oxide synthases: regulation and function. Eur Heart J. 2012:33:829-37.

31. Jones DP, Sies H. The redox code. Antioxid Redox Signal. 2015;23:734-46.

32. Thomas DD, Heinecke JL, Ridnour LA, Cheng RY, Kesarwala AH, Switzer $\mathrm{CH}$, et al. Signaling and stress: the redox landscape in NOS2 biology. Free Radic Biol Med. 2015;87:204-25.

33. Song $\mathrm{P}$, Zou $\mathrm{M}-\mathrm{H}$. Redox regulation of endothelial cell fate. Cell Mol Life Sci. 2014;71:3219-39.

34. Jackson SP. Arterial thrombosis - insidious, unpredictable and deadly. Nat Med. 2011:17:1423-36.

35. Kremen M, Krishnan R, Emery I, Hu JH, Slezicki KI, Wu A, et al. Plasminogen mediates the atherogenic effects of macrophage-expressed urokinase and accelerates atherosclerosis in apoE-knockout mice. Proc Natl Acad Sci. 2008;105:17109-114.

36. Duru EA, Fu Y, Davies MG. Role of formic receptors in soluble urokinase receptor-induced human vascular smooth muscle migration. J Surg Res. 2015;195:396-405

37. Tanski WJ, Fegley AJ, Roztocil E, Davies MG. Domain-dependent action of urokinase on smooth muscle cell responses. J Vasc Surg. 2004; 39:214-22.

38. Koshelnick Y, Ehart M, Hufnagl P, Heinrich PC, Binder BR. Urokinase receptor is associated with the components of the JAK1/STAT1 signaling pathway and leads to activation of this pathway upon receptor clustering in the human kidney epithelial tumor cell line TCL-598. J Biol Chem. 1997;272:28563-7.

39. Mahmood N Mihalcioiu C, Rabbani SA Multifaceted role of the urokinase-type plasminogen activator (UPA) and its receptor (UPAR): diagnostic, prognostic, and therapeutic applications. Front Oncol. 2018;8:24.

40. Carmeliet $\mathrm{P}$, Moons L, Lijnen R, Baes M, Lemaître V, Tipping P, et al. Urokinase-generated plasmin activates matrix metalloproteinases during aneurysm formation. Nat Genet. 1997;17:439-44.

41. Gong Y, Hart E, Shchurin A, Hoover-Plow J. Inflammatory macrophage migration requires MMP-9 activation by plasminogen in mice. J Clin Invest. 2008;118:3012-24

42. Dollery C, Libby P. Atherosclerosis and proteinase activation. Cardiovasc Res. 2006;69:625-35.

43. Farris SD, Hu JH, Krishnan R, Emery I, Chu T, Du L, et al. Mechanisms of urokinase plasminogen activator (UPA)-mediated atherosclerosis. J Biol Chem. 2011;286:22665-7. 


\section{S.J. Custodio-Chablé, et al.: Plaquetas, aterosclerosis e inflamación}

44. Weber $\mathrm{C}$, Noels $\mathrm{H}$. Atherosclerosis: current pathogenesis and therapeutic options. Nat Med. 2011;17:1410-22.

45. Badrnya S, Butler LM, Söderberg-Naucler C, Volf I, Assinger A. Platelets directly enhance neutrophil transmigration in response to oxidised low-density lipoprotein. Thromb Haemost. 2012;108:719-29.

46. Chinetti-Gbaguidi G, Colin S, Staels B. Macrophage subsets in atherosclerosis. Nat Rev Cardiol. 2015;12:10-7.

47. Vieira-de-Abreu A, Campbell RA, Weyrich AS, Zimmerman GA. Platelets: versatile effector cells in hemostasis, inflammation, and the immune continuum. Semin Immunopathol. 2012;34:5-30

48. Patkó Z, Császár A, Acsády G, Őry I, Takács É, Fưrész J. Elevation of monocyte-platelet aggregates is an early marker of type 2 diabetes. Interv Med Appl Sci. 2012;4:181-5

49. Li N. Platelet-lymphocyte cross-talk. J Leukoc Biol. 2008;83:1069-78.

50. Semple JW, Italiano JE, Freedman J. Platelets and the immune continuum. Nat Rev Immunol. 2011;11:264-74.

51. Nording HM, Seizer P, Langer HF. Platelets in inflammation and atherogenesis. Front Immunol. 2015;6:3378-84.

52. Yáñez-Mó M, Siljander PRM, Andreu Z, Bedina Zavec A, Borràs FE, Buzas El, et al. Biological properties of extracellular vesicles and their physiological functions. J Extracell Vesicles. 2015;4:27066.

53. El Andaloussi S, Mäger I, Breakefield XO, Wood MJA. Extracellular vesicles: biology and emerging therapeutic opportunities. Nat Rev Drug Discov. 2013;12:347-57

54. Milasan A, Tessandier N, Tan S, Brisson A, Boilard E, Martel C. Extracellular vesicles are present in mouse lymph and their level differs in atherosclerosis. J Extracell Vesicles. 2016;5:1-9.

55. Melki I, Tessandier N, Zufferey A, Boilard E. Platelet microvesicles in health and disease. Platelets. 2017;28:214-21.

56. Owens AP, Mackman N. Microparticles in hemostasis and thrombosis. Circ Res. 2011;108:1284-97.

57. Alexandru N, Andrei E, Dragan E, Georgescu A. Interaction of platelets with endothelial progenitor cells in the experimental atherosclerosis: role of transplanted endothelial progenitor cells and platelet microparticles. Biol Cell. 2015;107:189-204.

58. Rautou P-E, Vion A-C, Amabile N, Chironi G, Simon A, Tedgui A, et al. Microparticles, vascular function, and atherothrombosis. Circ Res. 2011;109:593-606.
59. Silverstein RL. Inflammation, atherosclerosis, and arterial thrombosis: role of the scavenger receptor CD36. Cleve Clin J Med. 2009;76(Suppl 2):S27-S30.

60. Oesterle A, Laufs U, Liao JK. Pleiotropic effects of statins on the cardiovascular system. Circ Res. 2017;120:229-43.

61. Owens AP, Passam FH, Antoniak S, Marshall SM, McDaniel AL, Rudel L, et al. Monocyte tissue factor-dependent activation of coagulation in hypercholesterolemic mice and monkeys is inhibited by simvastatin. J Clin Invest. 2012;122:558-68.

62. Violi F, Calvieri C, Ferro D, Pignatelli P. Statins as antithrombotic drugs. Circulation. 2013;127:251-7.

63. Pignatelli $\mathrm{P}$, Carnevale R, Pastori D, Cangemi R, Napoleone L, Bartimoccia S, et al. Immediate antioxidant and antiplatelet effect of atorvastatin via inhibition of Nox2. Circulation. 2012;126:92-103.

64. von Hundelshausen $P$, Schmitt MMN. Platelets and their chemokines in atherosclerosis - clinical applications. Front Physiol. 2014;5:1-17.

65. Coban E, Afacan B. The effect of rosuvastatin treatment on the mean platelet volume in patients with uncontrolled primary dyslipidemia with hypolipidemic diet treatment. Platelets. 2008;19:111-4.

66. Khayata M, Gabra JN, Nasser MF, Litman GI, Bhakta S, Raina R. Comparison of clopidogrel with prasugrel and ticagrelor in patients with acute coronary syndrome: clinical outcomes from the national cardiovascular database ACTION registry. Cardiol Res. 2017;8:105-10.

67. Angiolillo DJ, Capodanno D, Goto S. Platelet thrombin receptor antagonism and atherothrombosis. Eur Heart J. 2010;31:17-28.

68. Tello-Montoliu A, Tomasello SD, Ueno M, Angiolillo DJ. Antiplatelet therapy: thrombin receptor antagonists. Br J Clin Pharmacol. 2011;72:658-71.

69. Teng R. Ticagrelor: pharmacokinetic, pharmacodynamic and pharmacogenetic profile: an update. Clin Pharmacokinet. 2015;54:1125-38.

70. Tang $Y$, Zhang $Y-C$, Chen $Y$, Xiang $Y$. Efficacy and safety of cangrelor for patients with coronary artery disease: a meta-analysis of four randomized trials. Int J Clin Exp Med. 2015;8:800-8.

71. Iversen A, Galatius S, Jensen J. The optimal route of administration of the glycoprotein Ilb/Illa receptor antagonist abciximab during percutaneous coronary intervention; intravenous versus intracoronary. Curr Cardiol Rev. 2008:4:293-9.

72. Bledzka K, Smyth SS, Plow EF. Integrin Ilb 3: from discovery to efficacious therapeutic target. Circ Res. 2013;112:1189-200. 